\title{
Sinusitis and Respiratory Disease at Pediatric Age
}

\author{
Francisco Muñoz-López ${ }^{1,2}$ \\ 1 Pediatric Immunology Center, Barcelona 08028, Spain \\ 2 Former Head of the Department of Pediatric Immunoallergology, Hospital Clinic, Faculty of Medicine, \\ University of Barcelona, Barcelona 08028, Spain; 5314fml@comb.cat
}

Academic Editor: César Picado

Received: 7 March 2016; Accepted: 11 May 2016; Published: 31 May 2016

\begin{abstract}
Here, we present a review of the development of paranasal sinuses and pathologies associated to them, allergic and/or infectious sinusitis, in children. A review of 200 medical records of children and adolescents affected with respiratory disease is carried out. 66 patients (33\%) were diagnosed with sinusitis, six of which did not present any other respiratory processes. Of the remainder, association with rhinitis, asthma, or wheezy bronchitis, and one case with immune deficiency, was found. Other associated pathologies, such as cystic fibrosis, bronchiectasis, and other processes described as associated with sinusitis, were not detected in any case.
\end{abstract}

Keywords: sinusitis; rhinitis; asthma; wheezy bronchitis; children; adolescents

\section{Introduction}

The first step in the study of any child with repeated respiratory processes, either in the upper airways or the tracheobronchial tree, is to ascertain the state of the paranasal sinuses. The examination should be carried out at a very early age, even from the first year in which the maxillary sinuses are sufficiently developed to be seen on a properly executed radiological examination, in which signs of inflammation that might be responsible for recurrent clinical picture may be evident.

Nearly two-thirds of children with recurrent spastic bronchopaties suffer from sinusitis; this occurs at a rate approximately equal in children with extrinsic bronchial asthma to those with wheezy bronchitis.

It is well known that the paranasal sinuses are not fully developed during infancy, but evolve during childhood, with a time line that differs among the various sinus pairs. This asynchrony conditions their pathology and special features in childhood.

The maxillary sinuses are already visible in the 3rd-4th month of intrauterine life, as well as the ethmoidal sinuses, as an out-pouching of the mucous membrane of the nasal meatus, reaching $7 \times 4 \times 4 \mathrm{~mm}$ in size at birth, with an annual increase of about $2 \mathrm{~mm}$ high and $3 \mathrm{~mm}$ in the anteroposterior direction. With these measures, the maxillary sinuses are already radiologically visible from the second year of age, just like the ethmoidal sinuses, and are susceptible to an early disease, while the frontal sinuses evolve more slowly and it is not until 3-6 years of age that their image can be seen [1,2]. The maxillary sinus communicates with the nasal cavity through a small hole, through which the mucus secretion produced by various glands drains.

Due to this early development, the maxillary sinuses together with the ethmoidal sinuses are susceptible to sickness more often in younger children, with a clear net predominance of the former given their anatomical location. They share symptoms common to many diverse processes that must be taken into consideration in the differential diagnosis.

Maxillary sinusitis can be a single entity of infectious cause, but we must not forget that the mucosa of the sinuses is part of the lining of the entire respiratory tree and therefore often coincides with rhinitis (rhinosinusitis) or with asthma, having found that up to $73 \%$ of children between 2 and 6 years of age with allergic pathology can suffer from long-evolution maxillary sinusitis [3,4]. 


\section{Symptomatology}

The symptoms of sinusitis in children, mostly of the maxillary location, are essentially different from those found in adults. They are not so intense or severe, but manifests themselves with a latent focus, often because of recurrence of infectious processes of the upper respiratory tract and even the bronchial tree. For this reason, the discovery of sinusitis in children is often the result of a routine examination carried out in cases of bronchial or recurrent infection of the upper airways or of persistent and nocturnal cough [5-7].

The more specific symptoms include persistent rhinorrhea, which, if unilateral and accompanied by mucus-pus, indicates the possibility of bacterial sinusitis. If it is bilateral and accompanied by mucus fluid, it may correspond to allergic rhinosinupathy.

Nocturnal cough, sometimes afflicting these children, may be caused by sinus secretion that drains more easily from the cavity with the lateral or supine decubitus adopted during sleep.

Unlike in adults, headache in children is exceptional because frontal sinusitis is more common in the former.

Ethmoidal sinusitis, which may affect the infant, results in palpebral edema, particularly affecting the lower eyelid unilaterally. It is very typically due to its paranasal location.

General symptoms include paleness, anemia, and anorexia, common signs of any long-term infection, such as sinusitis. These symptoms that go with repeated respiratory infections should lead to an investigation of a possible sinupathy.

Symptoms rarely resemble those found in adults. They are characterized by intensity and are further evidence of local symptoms, particularly with respect to the classic painful points; this occurs more in older children, except in ethmoid sinusitis, which can affect the infant, as we already mentioned, appearing with obvious intensity and signs of severity [8].

\section{Diagnosis}

Due to its frequency, prolonged coughing would raise suspicion of maxillary sinusitis, which is confirmed by viewing an image of the sinuses. Traditionally, radiology has been enough to get demonstrative images with a classic Waters' occipito-mental projection or other positions, even in very young children. More recently, other less risky techniques, such as computed tomography or magnetic resonance imaging, have been introduced. High-definition computed tomography (CT) scans allow for tomographic slices in coronal and axial direction, which display in great detail and at the same time, both the bone structure and the soft tissue, including the sinusal mucosa. However, a study of 134 patients by radiology (Water' projection) and CT demonstrate that plain radiography has a sensitivity of $68 \%$ and a specificity of $87 \%$. In definitive, this and other studies show that the diagnostic performances of Waters' projection are able to maintain a role for radiography in the diagnosis. On the other hand, magnetic resonance imaging provides data in three dimensions, offering very valuable information in doubtful cases, being especially useful for viewing ethmoidal and sphenoidal sinuses [9-13].

Despite the advantages of these techniques, the need to sedate young children, and economic reasons, make radiology has not lost ground, except when images are not enough to provide demonstration. Images show the thickening of the mucosa, the total or partial opacification of the sinus, liquid levels, mucous, and, more rarely, polyps or calcifications corresponding to other pathological facts. After appropriate treatment, it is advisable to check the disappearance of pathological signs previously observed.

Although some allergic children may suffer from allergic sinusitis several times (recurrent sinusitis), given this circumstance, it is necessary to ensure that there is no other diseases, as sinusitis may accompany various pathological processes that are only occasionally expressed by this local pathology. This can occur with selective IgA deficiency, also present in a large number of allergic patients (1/200 vs. 1/700 in the general population), and with transient hypogammaglobulinemia in 
childhood, which is usually compensated within five years of age. Other immunodeficiencies have a wider expression with serious infections of various localizations [14,15].

Another process to be considered is cystic fibrosis, in which it is common that both sinuses are filled by the increased viscosity of secretions, sometimes associated with polyposis. Other processes are rarer, such as Kartagener syndrome in which sinupathy is one of its features along with the situs inversus, bronchiectasis, and cilia immobility. In other clinical profiles, such as primary ciliary dyskinesia, polyposis, and alpha-1-antitrypsin, maxillary sinuses may be equally affected $[16,17]$.

Consequently, given the high frequency of maxillary sinusitis in children with cough, bronchitis, or asthma, it is advisable to include paranasal sinuses X-rays in the diagnostic routine of these processes [4].

\section{Clinical Study}

In a review of 200 children, all with respiratory symptoms, we selected a total of 66 seen when they were aged between 15 months and 14 years and 7 months, and all were diagnosed with sinusitis (33\%). In 30 of them, this was caused by an allergy. In 16 others, it was due to infection. The remaining 20 had mixed or uncertain origins. Only 6 of them showed no association with other respiratory processes (tracheobronchitis, asthma, wheezy bronchitis). In another 5, different allergic diseases (eczema, urticaria, food, medicament) were found, and only one patient was diagnosed with immunodeficiency, data collected in Table 1. The table also shows the number of patients whose serum variations of the various immunoglobulins were found, without a direct relationship of their variations of the three types of sinusitis mentioned above, except for those of allergic cause ( $\uparrow \operatorname{IgE})$. In 9 cases, the levels were normal.

Table 1. Clinical and immunological study.

\begin{tabular}{|c|c|c|c|c|c|c|c|c|c|c|}
\hline \multirow{2}{*}{$\begin{array}{c}\text { Family Precedent } \\
\text { of Atopy: } \\
\text { Parents, } \\
\text { Grandparents }\end{array}$} & \multirow{2}{*}{$\begin{array}{c}\text { Age at } \\
\text { Diagnosis }\end{array}$} & \multicolumn{3}{|c|}{ Other Respiratory Processes } & \multirow{2}{*}{$\begin{array}{l}\text { Other } \\
\text { Allergic } \\
\text { Processes }\end{array}$} & \multirow{2}{*}{$\begin{array}{l}\text { Immuno- } \\
\text { Deficiency }\end{array}$} & \multicolumn{4}{|c|}{ Immunoglobulins } \\
\hline & & Rhinitis & Asthma & Wheezing & & & IgE & IgG & IgM & $\operatorname{Ig} \mathbf{A}$ \\
\hline 34 cases & $\begin{array}{l}15 \text { months- } \\
14 \text { years/ } \\
7 \text { months }\end{array}$ & 34 & 40 & 15 & 5 & 1 & $\begin{array}{c}\uparrow \\
50\end{array}$ & $\begin{array}{l}\uparrow 16 \\
\downarrow 13\end{array}$ & $\begin{array}{c}\uparrow 31 \\
\downarrow 0\end{array}$ & $\begin{array}{c}\uparrow 12 \\
\downarrow 5\end{array}$ \\
\hline
\end{tabular}

For none of the patients was family history of respiratory processes listed as associated with sinusitis (cystic fibrosis, etc.), so the possible hereditary factor thereof was discarded.

In a previous study of 100 medical records of children under 18 years old visited consecutively, with symptoms suggestive of asthma, rhinitis, or other respiratory conditions (bronchopaties) mentioned above, it was found that $38 \%$ of them suffered from sinusitis, either as an exclusive process or linked to other respiratory disorders processes, as summarized in Table 2 [18].

Table 2. Summary of the study of 100 clinical cases.

\begin{tabular}{ccccc}
\hline & Preschool & School & Adolescent & Total \\
\hline Rhinitis only & 0 & 20 & 10 & 30 \\
Asthma only & 9 & 8 & 1 & 18 \\
Asthma and rhinosinusitis & 7 & 4 & 7 & 18 \\
Bronchopathy only & 11 & 3 & 0 & 14 \\
Bronchopathy and rhinosinusitis & 4 & 5 & 0 & 9 \\
Rinosinusitis only & 8 & 2 & 1 & 11 \\
Total sinusitis (\%) & $\mathbf{1 9 ( 4 8 . 7 )}$ & $\mathbf{1 1 ( 2 6 . 1 )}$ & $\mathbf{8 ( 4 2 . 1 )}$ & $\mathbf{1 0 0}$ \\
\hline
\end{tabular}

Total sinusitis: $\mathbf{3 8 \%}$ 


\section{Conclusions}

In both studies, the high incidence of sinusitis in children is confirmed. It was predominant in smaller children - as the sole condition in some of them; in others, with rhinitis, asthma, or other respiratory conditions-but in none was found the existence of other processes that have been linked to the existence of sinupathy, such as the aforementioned bronchiectasis, cystic fibrosis, Kartagener syndrome, etc. Nevertheless, we have seen partial deficits of some immunoglobulins, which could facilitate the infectious cause of sinusitis.

In short, the high frequency of sinusitis, alone or linked to other respiratory conditions, requires appropriate testing. Radiology is the easiest and sometimes sufficient; however, if necessary, other techniques mentioned (computed tomography or magnetic resonance imaging) could be used in all children who present symptoms suggestive of sinusitis.

Conflicts of Interest: The author declares no conflict of interest.

\section{References}

1. Adibelli, Z.H.; Songu, M.; Adibelli, H. Paranasal sinus development in children: A magnetic resonance imaging analysis. Am. J. Rhinol. Allergy 2011, 25, 30-35. [CrossRef] [PubMed]

2. Shah, R.K.; Dhingra, K.; Carter, B.L.; Rebeiz, E.E. Paranasal sinus development: A radiographic study. Laryngoscope 2003, 113, 205-209. [CrossRef] [PubMed]

3. Nguyen, K.L.; Corbet, M.L.; García, D.P.; Eberly, S.M.; Massey, E.N.; Le, H.T.; Shearer, L.T.; Karibo, J.M.; Pence, H.L. Chronic sinusitis among pediatric patients with chronic respiratory complaints. J. Allergy Clin. Immunol. 1993, 92, 824-830. [CrossRef]

4. Bachert, C.; Patou, J.; van Cauwenberge, P. The role of sinus disease in asthma. Curr. Opin. Allergy Clin. Immunol. 2006, 6, 29-36. [CrossRef] [PubMed]

5. McQuillan, L.; Crane, L.A.; Kempe, A. Diagnosis and management of acute sinusitis by pediatricians. Pediatrics 2009, 123, 193-198. [CrossRef] [PubMed]

6. Esposito, S.; Bosis, S.; Bellasio, M.; Proncipi, N. From clinical practice to guidelines; how to recognize rhinosinusitis in children. Pediatr. Allergy Immunol. 2007, 18 (Suppl. S18), 53-55. [CrossRef] [PubMed]

7. Marseglia, G.L.; Castellazzi, A.M.; Licari, A.; Marseglia, A.; Leone, M.; Pagella, F.; Ciprandi, G.; Klersy, C. Inflammation of paranasal sinuses: The clinical pattern is age-dependent. Pediatr. Allergy Immunol. 2007, 18 (Suppl. S18), 10-12. [CrossRef] [PubMed]

8. Kashani, S.; Carr, T.F.; Grammer, L.C.; Schleimer, R.P.; Hulse, K.E.; Kato, A.; Kern, R.C.; Conley, D.B.; Chandra, R.K.; Tan, B.K.; et al. Clinical characteristics of adults with chronic rhinosinusitis and specific antibody deficiency. J. Allergy Clin. Immunol. Pract. 2015, 3, 236-242. [CrossRef] [PubMed]

9. Kolawole, S.; Okuyemi, M.D.; Terance, T. Tsue. Radiologic imaging in the management of sinusitis. Am. Fam. Phys. 2002, 10, 1882-1886.

10. Triulzi, F.; Zipoli, S. Imaging techniques in the diagnosis and management of rhinosinusitis in children. Pediatr. Allergy Immunol. 2007, 18 (Suppl. S18), 46-49. [CrossRef] [PubMed]

11. Leo, G.; Triulzi, F.; Consonni, D.; Cazzavillan, A.; Incorvaia, C. Reappraising the role of radiography in thr diagnosis of chronic rhinosinusitis. Rhinology 2009, 47, 271-274. [PubMed]

12. Konen, E.; Faibel, M.; Kleinbaum, Y.; Wolf, M.; Lusky, A.; Hoffman, C.; Eyal, A.; Tadmor, R. The value of the occipital (Waters') view in diagnosis of sinusitis: A comparative study with computed tomography. Clin. Radiol. 2000, 55, 856-860. [CrossRef] [PubMed]

13. Diament, M.J. The diagnosis of sinusitis in infants and children X-ray, computed tomography and magnetic resonance imaging. J. Allergy Clin. Immunol. 1992, 90, 442-444. [CrossRef]

14. Costa Carvalho, B.T.; Tiemi Nagao, A.; Arslanian, C.; Carneiro Sampaio, M.M.S.; Naspitz, C.H.K.; Sorensen, R.U.; Solé, D. Immunological evaluation of allergic respirtory children with recurrent sinusitis. Pediatr. Allergy Immunol. 2005, 16, 534-538. [CrossRef] [PubMed]

15. Guilemany, J.M.; Mullol, J.; Picado, C. Relaciones entre rinosinusitis y bronquiectasias. Arch. Bronconeumol. 2006, 42, 135-140. [CrossRef] [PubMed] 
16. Antunes, J.; Fernandes, A.; Miguel-Borrego, L.; Leiria-Pinto, P.; Cavaco, J. Cystic fibrosis, atopy asthma and ABPA. Allergol. Immunopathol. 2010, 38, 278-284. [CrossRef] [PubMed]

17. Berdon, W.E.; Willi, U. Situs inversus, bronchiectasis and sinusitis its relation to immotile cilia history of the diseases and their discovers-Manes Kartagener and Bjorn Afzelius. Pediatr. Rinol. 2004, 34, 38-42.

18. Muñoz-López, F. Sinusitis asociada a patología respiratoria alérgica. Rev. Esp. Pediatr. 2012, 69, 74-78.

(C) 2016 by the author; licensee MDPI, Basel, Switzerland. This article is an open access article distributed under the terms and conditions of the Creative Commons Attribution (CC-BY) license (http:/ / creativecommons.org/licenses/by/4.0/). 